\title{
METODOLOGIA FUNCIONAL INTEGRATIVA: RELAÇÃO DO DESEMPENHO MOTOR E COMPORTAMENTO DE INTERAÇÃO SOCIAL NA APRENDIZAGEM DO NADO CRAWL
}

Sara T. C. KROTH* , Jefferson T. CANFIELD*

\section{RESUMO}

O objetivo deste foi verificar o desempenho motor no nado crawl em adultos, após terem sido submetidos a uma metodologia voltada para a aprendizagem social (Metodologia Funcional Integrativa) e relacionar este desempenho motor com as comportamentos de interação social foi o objetivo deste estudo. A amostra intencional foi constituida por seis sujeitos adultos de ambos os sexos matriculados na Escolinha de Natação da ADUFSM. Durante doze aulas o professor foi um estimulador, nomeando atividades e incitando a participação dos alunos para a modificação de regras, resolução de conflitos, reflexões e discussões a respeito das atividades. No decorrer das aulas o grupo foi observado através do Sistema de Registro dos Comportamentos de Interação Social (SIRCIS). Ao final da faze experimental foi aplicado ao grupo um questionário de opinião sobre a experiência de trabalharem em uma metodologia não usual. Criou-se e validou-se uma Matriz de Análise do Nado Crawl (MAC), para verificar o desempenho motor dos Ss. Embora a MFI destaque as relações sociais observou-se que houve aprendizagem do nado crawl. Os resultados indicam que houve correlação significativa entre os escores do SIRCIS e da MAC. Constatou-se a motivação e alegria dos Ss. em envolverem-se em atividades motoras de orientação aberta.

UNITERMOS: aprendizagem motora, natação

\section{ABSTRACT \\ FUNCTIONAL INTEGRATED METHODOLOGY: RELATION OF MOTOR DEVELOPMENT AND SOCIAL BEHAVIOR INTERACTIONAN CRAWL STROKE}

To verify adults motor performance on crawl stroke, after they had been submited to a methodology directed towards social learning (Integrative Functional Methodology) was the purpose of this study. Six subjects of both 
sexes, from ADUFSM Swimming School were assigned as an intentional sample. During an experiment of twelve classes, the physical educator was a stimulator. She assigned activities and incited the students participation in changing rules, conducting reflections and discussions about the activity going on. In the course of the classes, the group was observed according to the Register System of Social Interaction Behavior (SIRCIS). At the end of the twelve classes a questionnaire was applied. It asked opinions about the experience of working on a methodology which was not commonly used. A Matrix of Analysis for Freestyle Swimming was created and validated in order to verify the motor performance of the subjects. The correlations between the scores of the SIRCIS and MAC was found to be significant. The Ss. showed high of motivation and happines by getting envolved in motor tasks with open orientation.

UNITERMS: motor learning, swimming

\section{INTRODUÇÃO}

O processo ensino-aprendizagem de natação, foi por muito tempo encarado de uma maneira bastante prescritiva e desvinculada dos princípios da aprendizagem motora. Em alguns métodos de ensino, a ação do professor se caracteriza pela diretividade e o principal objetivo é o ensino da destreza específica.

Ainda hoje, encontramos em livros, descrições exaustivas de exercícios que dão uma solução rápida e eficiente para a aquisição de melhores gestos propulsivos, deixando de lado questões elementares que dizem respeito aos alunos, à tarefa e às condições em que esta se desenvolve.

Considerando estas afirmações e com o intuito de procurar desenvolver outra dinâmica de trabalho no meio líquido, mais voltada para a aprendizagem social, realizou-se este estudo, onde propôs-se o uso da Metodologia Funcional Integrativa (MFI), baseada em pressupostos de Alberti \& Rothemberg (1975), que afirmam que este método introduz o conceito recreativo de edụcação do gesto desportivo, e sistematiza a metodologia global em séries de jogos que conduzem o aluno ao jogo final e série de exercícios paralelos explorando seńî́pre o espírito do jogo.

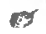

Teve-se como objetivo geral desenvolver o nado crawl através da MFI, verificando o desempenho motor e as interações sociais do grupo. Estabeleceu-se os seguintes objetivos específicos: 
a) Observar no aluno a interação social, a participação em aula, a participação na resolução de conflito, a aceitação nas mudanças de regras, as expressões de idéias para modificar regras, bem como a sua reação diante desta nova metodologia.

b) verificar a existência de correlação entre a MAC e a frequência dos alunos às aulas.

c) Verificar a existência de correlação entre os resultados do Sistema de Registro de Interação Social (SIRCIS) e o resultado da Matriz de Análise do Nado Crawl (MAC).

\section{METODOLOGIA}

Esta pesquisa caracteriza-se como pré-experimental. A seleção da mostra foi intencional e os sujeitos foram seis alunos, adultos, de ambos os sexos, matriculados na Escolinha de Natação da Associação Desportiva da Universidade Federal de Santa Maria.

Como pré-requisitos ao comportamento de entrada, os alunos deveriam: a) saber deslocar-se submersos; b) demonstrar segurança ao introduzirem o rosto na água; c) flutuar em decúbito dorsal e ventral na superfície da água.

No primeiro contato com o grupo comentou-se a respeito dos métodos usuais empregados na natação e como seria desenvolvido o trabalho com a MFI, deixando claro que esta metodologia introduz o conceito recreativo de educação do gesto desportivo e sistematiza o método global em séries de jogos ou atividades que conduzem o aluno ao objetivo final e série de exercícios paralelos usando sempre o espírito do jogo. Comentou-se também que esta metodologia está baseada no conceito recreativo da educação do gesto depostivo e na análise de interação dos jogos, sendo que nada seria imposto, que as aulas seriam desenvolvidas através da discussão, reflexão e interações, com a criação de papéis representativos pelos próprios alunos. Após, mostrou-se um vídeo, sem áudio, do nado crawl, para o conhecimento da tarefa.

A partir destes procedimentos, aplicou-se a MFI. Como estimulador do processo, o professor sugeriu atividades ou jogos e incentivou a participação dos alunos, chamando a atenção para detalhes do trabalho, dando-lhes a oportunidade da criação de papéis e enfatizando sempre a importância de todods participarem, deixando sempre bem claro que ao mesmo tempo em que se executa o jogo deviase explicitar o uso dos elementos do nado crawl. Algumas afividades no início foram sugeridas pelo professor, mas com o passar das aulas e o conhecimento do processo, os próprios alunos sugeriam atividades, como: "passagem por um túnel"(feito com aros na vertical); duas equipes e um aro fixo no bloco de saída, 
onde o objetivo era fazer gol; revezamento com uma pequena bola; "rabo do urso"; em duplas, ir de um extremo ao outro da piscina, passando um para o outro um objeto, cada aluno com movimentações diferentes; o jogo do lenço... Dentro desta perspectiva, a ação do professor foi a de buscar um clima de aceitação mútua, conforme o SIRCIS preconiza, entre ele e os alunos, fazendo-os sentir que o real objetivo da aula era de desenvolvermos o nado crawl com ênfase no aspecto lúdico (brincar, jogar, relacionar-se)

Os instrumentos de medida utilizados foram:

1) O Sistema de Registro dos Comportamentos de Interação Social (SIRCIS), para verificar a aprendizagem social. Este instrumento foi desenvolvido por BRACHT (1979), tendo como referencial os modelos de análise de ensino de Sant'Ana (1976), Underwood (1976), Heinila ( 1978) e Taylor (1979). A razão principal para o uso deste Sistema está na intenção de analizar o processo, ou seja, o decorrer das aulas e não somente o produto final. Usou-se fichas para observar os seguintes aspectos: nível de participação, contatos sociais, formação de subgrupos, participação na resolução de conflitos, aceitação de mudanças de regras e expressão de idéias para a mudança de regras.

2) Um questionário (QAA) de avaliação da forma, situações e conteúdo das aulas e objetiva compreender as reações dos alunos ao trabalharem com uma metodologia mais voltada para as relações sociais.

3) A Matriz Analítica do Nado Crawl (MAC), serviu para verificar o desempenho motor dos alunos no nado crawl e contém os elementos básicos do nado, como: o movimento alternado de penas, a movimentação coxo-femural, a entrada do braço na linha mediana do corpo, a tração do braço, o giro da cabeça no momento de inspirar o ar e a expiração quando o braço do mesmo lado terminasse a fase de tração. Esta matriz foi criada considerando o método do qual o grupo participou, ou seja, seríamos incoerentes se exigíssemos o máximo em termos de técnica perfeita aplicando um método não diretivo, que enfatiza mais a participação dos alunos no processo. A mesma foi validade por três profissionais da área de natação exercendo suas atividades na mesma escola em que foi desenvolvido o trabalho, sendo que analizou-se os ítens citados anteriormente e usou-se a pontuação máxima (2) para a execução correta, a pontuação intermediária (1) quando o movimento não apresentava-se totalnhente correto e zero (0) quando a execução apresentava-se fora do padrão do şovimento. Esta análise foi feita na última aula ao solicitarmos que o aluno tentasse deslocar de um extremo ao outro da piscina $(25 \mathrm{~m})$ procurando usar os elementos vistos no vídeo e enfatizados durante as aulas em forma de jogo. A matriz consta de seis (6) ítens e possui a pontuação máxima de doze (12) pontos. 


\section{RESULTADOS E DISCUSSÃO}

Da observação através do Sistema de Registro de Comportamentos de Interação Social (SIRCIS), fazemos um relato das dimensões de maior ocorrência e a respectiva discussão.

No ítem "Nível de Participação", 73.5\% do grupo demonstrou entusiasmo, expressou alegria, satisfação, prazer e euforia durante as aulas. Estes resultados convergem para a posição de Dietrich (1978) quando ele estabelece que uma aula de Educação Física deve propiciar ao aluno um sentimento de prazer, deve buscar euforia e espontaneidade na participação, se quizer promover a motivação para a prática continuada do esporte.

No ítem "Contatos Sociais", $78 \%$ da turma, durante as reflexões ou atividades manifestou-se de forma amigável e cordial. Segundo Thomas (19780 o contato entre os alunos é condição necessária quando pretende-se uma participação efetiva destes na organização das atividades das aulas e na superação de conflitos, quando se pretende questionar e modificar regras ou quando se pretende exercitar a cooperação. É possível numa aula de Educação Física, exercitarem-se importantes funções básicas do comportamento social, como a capacidade de comunicação para a melhoria do desempenho recíproco.

No ítem "Formação de sub-grupos", 55.3\% da turma quando solicitada a formação de grupos esperou ser chamada não assumindo, portanto qualquer atitude ou manifestação, entretanto, $30 \%$ da turma quando solicitada à formação de grupos apresentou comportamento de liderança.

No ítem "Participação na Resolução de Conflitos", 49.1\% do grupo quando envolvido num conflito participou expressando-se verbalmente, dando sugestões e reconhecendo erros; $48.8 \%$ somente participou quando solicitado. Estes resultados indicam que houve uma maior preocupação em expor os conflitos e de submetê-los à apreciação dos colegas. Considerando a utilização de jogos ou atividades para cuja realização o professor determinava previamente apenas os regras elementares, é natural que durante a realização dessas atividades surjam divergências sobre o "permitido"e o "não permitido".

No ítem "Aceitação das Mudanças de Regras, 75.7\% do grupo reagiu favoravelmente qundo ocorreram alterações na estrutura da atividade. Esta categoria somente foi utilizada qundo ocorreram decisões nas mudanças ou inclusão de regras no jogo.

No ítem "Mudanças de Regras", 48.5\% da turma espontaneamente deu idéias para mudanças durante o jogo. Na MFI, prevê-se o envolvimento dos alunos no processo de regulamentação dos jogos, o que implica, conforme Dietrich (1978), a criação pelos alunos de seus próprios papéis representativos. 
Da análise do questionário (QAA) aplicado aos alunos obtiveram-se os seguintes resultados:

Quando questionados sobre o fato de haverem sentido diferença na maneira como as aulas se sucederam, 100\% respondeu "sim".

Quando questionados "Que diferenças sentiu ?", o grupo destacou: - aulas mais descontraídas, masi interessantes, - o aprendizado ocorreu de forma mais natural, - participamos mais das aulas e, - aulas mais divertidas.

Quando questionados sobre a atuação do professor, a turma respondeu que lhes era permitido propor idéias, decidir sobre as atividades e proporcionando estímulos à integração entre colegas.

Quando questionados sobre que métodos mais gostou, 66\% da turma respondeu MFI e 33\% respondeu que gostou mais da Metodologia Parcial (desenvolvida no semestre anterior).

Finalmente quando questionados sobre qual método participou mais dando idéias, sugestões e relacionando-se com os colegas, $66 \%$ da turma respondeu que foi na MFI, $16.6 \%$ respondeu que em ambos (MFI e MP) e $16.6 \%$ respondeu que foi na metodologia parcial (MP).

TABELA 1 - Frequência às aulas, escores na MAC e escores no SIRCIS

\begin{tabular}{lllr}
\hline Alunos & F & MAC & SIRCIS \\
\hline A & 09 & 11 & 32.2 \\
B & 06 & 04 & 7.4 \\
C & 10 & 12 & 28.0 \\
D & 10 & 07 & 11.0 \\
E & 11 & 09 & 17.8 \\
F & 10 & 10 & 16.1 \\
\hline
\end{tabular}

Para determinar a existência de correlação entre o resultado da Matriz Analítica do Nado Crawl (MAC) e a frequência dos alunos às aulas; e a existência de correlação entre os escores do Sistema de Registro de Comportamento de Interação Social SIRCIS) e a Matriz Analítica do Nado Crawl (MAC), utilizou-se a Correlação de Pearson.

Os resultados relacionados ao segundo objetivo específico indicam que não existe uma correlação significativa entre a frequência dos alunos às aulas e o $\operatorname{MAC}(0,6764, \mathrm{P}=0,14)$.

$\mathrm{O}$ fato de não ter havido correlação entre a frequência dos alunos às aulas e os escores da MAC pode parecer uma contradição ao princípio da quantidade de 
prática como variável importante na aprendizagem de tarefas motoras, entretanto se observarmos na TABELA 1 podemos constatar que a variação na frequência (9 a 11 para 4 Ss) não representa uma fonte de variação que possa alterar os escores significativamente, porém a menor frequência (6) apresenta um escore significativamente menor. A quantidade de prática, é sem dúvida um dos fatores importantes no processo de aprendizagem, e para Maggil (1984) parece claro que quanto mais tentativas de prática uma pessoa executa em destrezas motoras, tanto melhor será o desempenho final, porém alerta que a quantidade de prática embora afete a qualidade da aprendizagem, o efeito não será sempre proporcional.

Houve correlação $(r=0,8820$ e $p=0,20)$ entre os escores da MAC e os escores do SIRCIS.

Quando nas aulas da MFI, colocamos aos alunos a necessidade de mudar as regras de determinado jogo, leváva-mos estes, a uma intensa atividade cognitiva. Embora a MFI destaque as relações sociais, pode-se constatar o aumento dos níveis de desempenho motor.

Nesta metodologia o fator relações sociais foi relevante, no entanto destacou-se o desempenho motor (nado crawl).

Maggil (1984) sugere que devemos dar atenção aos diversos tipos de comportamento, considerando quais resultados são desejados na situação de ensino-aprendizagem. Se a meta da educação é a educação do indivíduo como um todo, os procedimentos devem concorrer para que todos os domínios do comportamento sejam estimulados. Assim, nadar não será somente um ato motor, um resultado, um desempenho parcial.

\section{CONCLUSÕES}

Neste estudo, ao aplicar a Metodologia Funcional Integrativa, pretendeu-se verificar a participação mais direta e ativa no processo ensino-aprendizagem e, observou-se que isto foi atingido pois houve consciência da importância na modificação de regras, expressão de idéias, resolução de conflitos, enfim da modificação das formas usuais de trabalho no meio líquido.

Pode-se concluir também o quão importante é afastar-se de métodos puramente prescritivos considerando a satisfação dos alunos na busca de aprendizagem.

Uma forte característica no desenvolvimento das aulas foi asalegria dos alunos ao participarem de atividades com orientação lúdica yisando também o desempenho motor. Foi notória a euforia e satisfação do grupo ao sentir que através destas atividades mais descontraídas alcançaram bons resultados em termos de aprendizagem. 
A metodologia adotada proporcionou aos alunos serem agentes de sua própria educação através da discussão sobre normas de ação nos jogos e na participação das decisões de aula. A aprendizagem ocorreu orientada mais pelas necessidades e interesses e participação do aluno do que pela imposição técnica do movimento arbitrariamente estabelecidas.

\section{REFERÊNCIAS BIBLIOGRÁFICAS}

ALBERTI, H. e ROTHEMBERG, L.. Methodische ubungsreihn in spielen. Schorndorf - Sttutgart Karl Hofmann. Tradução de Valter Bracht, 1975.

BRACHT, V. A educação física escolar como campo de vivência social e de transformação de atitudes favoráveis à prática do desporto. Dissertaçào de Mestrado, não publicada. Universidade Federal de Santa Maria, 1983.

DIETRICH, K., et al , Sportpiel und interaktion. Ausschuss deutscher leibeserzuher: sozialisation im sport. Schorndorf. Tradução de Valter Bracht, 1978.

MAGGIL, R. A. Aprendizagem Motora: conceitos e aplicações. São Paulo: Edgard Blucher ltda, 1984.

THOMAS, A. Einfuhrung in dis sportpsychologia. Gottinger: Dr C. J. Hogrefe. Tradução de Valter Bracht, 1978. 